UNIVERSUM • Vol. 30 - No $1 \bullet 2015 \bullet$ Universidad de Talca

Las formas de la historia. Del discurso histórico del poder a las expresiones contrahistóricas en América Latina

Eliseo Lara

Pp. 137 a 151

\title{
LAS FORMAS DE LA HISTORIA. DEL DISCURSO HISTÓRICO DEL PODER A LAS EXPRESIONES CONTRAHISTÓRICAS EN AMÉRICA LATINA
}

\author{
Forms of history. Historical discourse of power \\ to against-histories expressions in Latin America
}

Eliseo Lara*

\section{RESUMEN}

El desarrollo de la novela histórica en América Latina en el último cuarto del siglo XX puso como eje temático en la teoría literaria las nuevas miradas sobre la Historia. En efecto, la multitud de voces que emergieron constituyeron un corpus difícil de abordar por una sola óptica, por lo que prontamente se comenzó un debate teórico acerca de este fenómeno literario: Nueva Crónica de Indias, Nueva Novela Histórica, Novela Neobarroca o Ficción de Archivo fueron los nombres que recibieron los principales enfoques teóricos que se hicieron cargo de esta problemática. Así, dentro de este ámbito insertamos nuestra discusión acerca de las formas de la historia, la cual se abre a partir de estos nuevos discursos críticos que irrumpieron desde la literatura sobre el relato oficial de nuestro pasado. Con una mirada transdisciplinar y recogiendo lo señalado por la Nueva Crónica de Indias abordamos las novelas El arpa y la sombra (1979) de Alejo Carpentier y Los perros del paraiso (1983) de Abel Posse, pues nos interesa rescatar el juego contrahegemónico y contradiscursivo que se hace sobre el tes-CUBRIMIENTO de América al rescatar y poner como base el imaginario histórico construido por los relatos oficiales, convirtiendo estas expresiones literarias en una forma contrahistórica.

Palabras clave: Nueva Crónica de Indias, contrahistoria, des-CUBRIMIENTO, El arpa y la sombra, Los perros del paraíso.

\footnotetext{
* Facultad de Educación, Universidad Andrés Bello. Viña del Mar, Chile. Correo electrónico: eliseolaraordenes@gmail.com
}

Artículo recibido el 28 de noviembre de 2013. Aceptado el 4 de noviembre de 2014. 


\begin{abstract}
The development of the historical novel in Latin America in the last quarter of the twentieth century took as its theme in literary theory new perspectives on history. Indeed, the multitude of voices that emerged were a difficult corpus to address a single optic, so soon a theoretical discussion of this literary phenomenon began: New Chronicle of Indian, New Historical Novel, Novel Neobarroca or Fiction Archive were the names that were the main theoretical approaches that care of this problem were made. Thus, within this field we insert our discussion about ways of history, which opens from these new critical discourses that broke from the literature on the official story of our past. With a look transdisciplinary and collecting those reported by the New Chronicle Indies boarded novels El arpa y la sombra (1979) by Alejo Carpentier and Los perros del paraíso (1983) by Abel Posse, because we want to rescue the game and against discursive that counterhegemonic done on the des-cOVERAGE America to rescue and put the basis of the historical imaginary constructed by official accounts, making these literary expressions in a way against history.
\end{abstract}

Keywords: New Chronicle of Indian, Against history, des-COVERAGE, The Harp and the Shadow, Dogs of paradise.

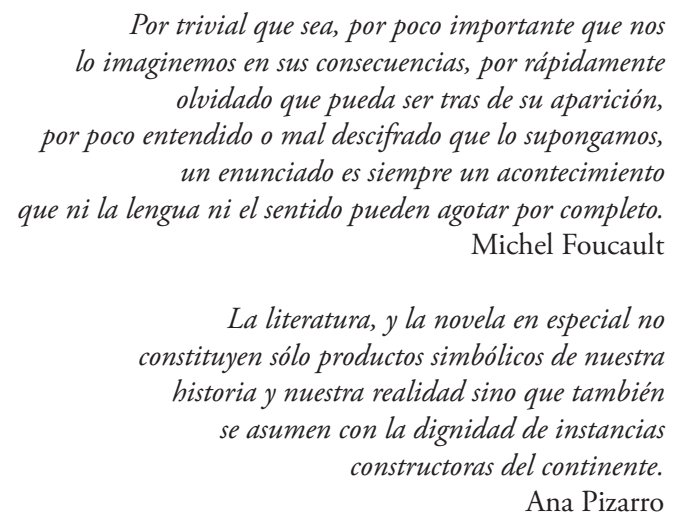

\title{
INTRODUCCIÓN
}

La discusión acerca de los puntos de articulación teórica sobre las obras literarias hispanoamericanas que abordan sucesos históricos ha permitido visualizar una serie de características comunes entre obras de diversos años de publicación, distintos autores y diferentes hechos referidos. Las Nuevas Crónicas de Indias o, también, como Nueva Novela Histórica, Novela Neobarroca o Ficción de Archivo fueron ópticas que definieron y establecieron características compartidas en 
amplios corpus de novelas (Viu, 2007). No obstante, nos parece relevante seguir utilizando el término acuñado por Alejo Carpentier en su conferencia La novela latinoamericana en visperas del nuevo siglo de 1979 en la Universidad de Yale, pues en dicha ocasión el escritor cubano exhorta, como señala Carolina Pizarro, a sus compañeros de oficio a asumir un rol: el de ser los nuevos cronistas de Indias. Este llamado de Carpentier dejó abierta una vasta comprensión acerca de lo que refería, ya que no sólo involucró el sentido histórico de la novela sino también el de construcción de un imaginario de presente y futuro contraponiéndose a lo que habían hecho los antiguos cronistas sobre nuestras tierras. De ahí entonces, que nos parece necesario y oportuno conservar este término, pues se relaciona tanto en su sentido histórico, teniendo como hecho referencial el tes-CUBRIMIENTO, como también en el de constructor de un imaginario, pero esta vez con voces propias de estas tierras y conscientes de lo sucedido.

No obstante, la historia sobre América ha sido un tema puesto en discusión desde el propio registro de los europeos, sin dejar de considerar aquellos poquísimos textos historiográficos prehispánicos que resistieron los embates de la invasión ni los posteriores escritos indígenas que intentaban dar cuenta de su propio pasado, aun cuando estos poseen una forma totalmente extranjera producto de las propias exigencias de la Corona.

Tanto en Perú como en México el único sector aborigen capacitado para conservar parte de la vieja memoria histórica y de las técnicas para recoger los hechos del pasado fue el reducido grupo de indígenas principales descendientes de la antigua clase dirigente prehispánica. Ellos fueron los que de manera coherente trasmitieron en la época colonial las pictografías y recuerdos indígenas y permitieron la aparición de una literatura histórica mestiza, que se valía de los procedimientos europeos (Guerra, 2009: 73) ${ }^{1}$.

La forma de contar la Historia en nuestras tierras desde hace más de cinco siglos se impuso con condicionantes ligados a lo político y lo social, con un fuerte sentido representacional de los grupos dominantes aún cuando estos fueran los mismos aborígenes, pues se les hacía ver su privilegio en el nuevo orden social que

\footnotetext{
${ }^{1}$ Cabe indicar que este tipo de textos era exigido por la Corona española para acreditar el pasado noble de los aborígenes y hacerlos parte del aparato colonial, lo cual llevó a que muchos de estos historiadores indígenas y mestizos describieran un pasado prehispánico engrandecido, en forma de libros y en español. "Ejemplo de ello lo proporciona en el Virreinato de Nueva España Hernando Alvarado Tezozómoc (1519-1609), quien era hijo del penúltimo tlatoani de Tenochtitlán (Cuitlahuac) -lo que parece no estar totalmente comprobado- con la heredera de Moctezuma, aunque no cabe duda que se crió entre la elite que había gobernado el valle de México antes de la llegada de los espańoles. Eso explica que su padre fuera después de la conquista (1539) gobernador indígena de México-Tenochtitlán, ciudad en la que había nacido Tezozómoc" (Guerra, 2009: 75).
} 
se imponía en la Colonia, cuestión que evidencia la lógica de la distinción de clases que, como seńaló Marx en 1848, era propia de la Historia.

Así, dentro de este marco referencial, nos adentraremos en un cruce respecto de las formas de la Historia desde las novelas El arpa y la sombra (1979) de Alejo Carpentier y Los perros del paraíso (1983) de Abel Posse, pues nos interesa rescatar el juego contrahegemónico y contradiscursivo que se hace sobre el desCUBRIMIENTO de América al rescatar y poner como base el imaginario histórico construido por los relatos oficiales, convirtiendo a estas expresiones literarias en una forma contrahistórica que somete a crítica, sospecha, desconfianza y burla a la historia oficial.

\section{LOS QUIEBRES DE LA HISTORIA COMO DISCIPLINA. UN LEGADO PUESTO EN CRISIS}

El quiebre paradigmático que significó el triunfo de la Revolución Cubana para América Latina y el Caribe no trajo solo consecuencias políticas, sino también de tipo social y cultural, pues Cuba hizo, como ningún otro país, una promoción y revisión investigativa acerca del arte, la literatura y la historia de nuestro continente, creando espacios de encuentro y debate sobre las formas negadas de nuestro pasado cultural. Las ideas marxistas que promovían el estudio de la historia en su sentido material y la aspiración de cambiar el rumbo de la misma reforzaron los diferentes proyectos historiográficos que venían motivando esa vuelta hacia nuestras propias condiciones y concepciones del mundo, que para el caso de la novela se venía desplegando en forma creciente desde mediados del siglo XIX, aun cuando la crítica "oficial" y universalista haya reconocido tal producción recién un siglo después, en los años 60 del siglo XX, denominándola como boom. No obstante, y tal como lo señala José Donoso, la denominación que tuvo este fenómeno de "boom" estaba "cargado de connotaciones peyorativas o sospechosas, menos, quizás, el reconocimiento de dimensión y de superabundancia” (1987: 11) puesto que se pretendía hacer ver que el flujo de la novela en América era ex nihilo.

En este sentido, entonces, vemos que ocurre un desplazamiento hacia otras formas de abordar nuestro pasado, ya que como bien señala Patricia Bouzas debemos recordar que:

La coartada "natural" justificó, entre otras cosas, las relaciones de poder, es decir la distribución "naturalmente establecida" entre poseedores y no poseedores. El marxismo es, precisamente, el discurso que viene a cuestionar ese axioma del capitalismo al colocar aquellas mismas relaciones de poder como producto de cada momento histórico preciso (2004: 31). 
La Teoría de la Dependencia y el conjunto de lineamientos acerca de la Liberación de nuestro continente fueron expresados en una pedagogía, filosofía, teología e historia, pero también tuvo su expresión en una literatura, que con otras conceptualizaciones teóricas apuntó hacia una misma dirección, siendo parte del conjunto de "voces de protesta contra el eurocentrismo" (Pizarro, 2010: 228) característica principal que el pensamiento de la Liberación venía a plantear.

Por otra parte, la defensa de la Historia sobre sus formas de construcción en América fue perdiendo aun más fuerza, puesto que desde hacía un tiempo se venía instalando en la filosofía de la historia un cuestionamiento acerca de sus prácticas y de las metodologías de reconstrucción historiográfica que utilizaba la disciplina. Autores como White (1978), Foucault (1970), Ricouer (1985), Danto (1965) o Mink (1987) desarrollaron una crítica filosófica que puso en discusión los métodos y las funciones de la disciplina, pues como hace notar Verónica Tozzi:

El cuestionamiento tiene una doble dimensión: política y epistémica. En términos políticos, se denuncia a la historiografía tradicional porque, en su exclusiva atención a perspectivas de élites políticas o, alternativamente por interesarse en el develamiento de los procesos históricos de gran escala que subyacen en las interacciones humanas eliminando cualquier perspectiva subjetiva, se ha "olvidado" de "otros" actores, de "otras" agencias, "otras" voces [...] En términos epistemológicos, desarrollos en la filosofía y en las ciencias sociales, imbuidos de los efectos del giro lingüístico, denuncian hasta qué punto los historiadores subestiman las dificultades de representar objetivamente y con verdad el pasado (2009: 169-170).

Con lo anterior, vemos de qué manera la Historia comenzó a ser problematizada como disciplina, pero ya no solo en su vínculo con el poder y sus relaciones de distribución, sino también en las formas por la cual se expresa, pues el silenciamiento de las "otras" voces, en este caso las originarias de nuestras tierras, ha significado un vacío del pasado que tendió a rellenarse con discursos ajenos o sobre exigidos y condicionados por los invasores, haciendo de América una extensión y, como muchos criollos han defendido hasta incluso hoy, una herencia de Europa. De ahí que cobra relevancia el concepto de Nueva Crónica de Indias propuesto por Carpentier y las obras que analizaremos, ya que su enfoque crítico consistió en recoger lo señalado como verdad y desde ahí problematizar las formas de la historia con un discurso que entendemos como una expresión de contrahistoria. 


\section{HISTORIOGRAFÍA Y REPRESENTACIÓN, UN PROBLEMA DE LOS USOS DEL DISCURSO}

La imagen que podemos construir sobre el pasado está, sin dudas, mediada por lo dicho acerca de él, sin embargo existe un predominio de asumir con mayor vehemencia el discurso formal e institucional e, incluso, con mayor fuerza en los casos en que solo accedemos a él por lo relatado por otros y no por un mero acto rememorativo de una experiencia personal. Esta situación ha ayudado al desarrollo de una homogeneidad imaginaria que se genera en cada sociedad y que incluso marca diferencias por los recortes ópticos que se hacen de aquel pasado. Se nos cuenta algo no con total transparencia ni cabalidad sino simplemente lo que interesa resaltar o rescatar de lo pretérito. En este sentido, la Historia tiene fines asociados y cuestiones políticas e ideológicas que le subyacen a su práctica. Por tal motivo, nuestro objeto consiste no en negar la Historia, sino en cuestionar su práctica desde discursos que asumieron la responsabilidad de hacernos pensar y al menos cuestionar este pasado relatado por una institucionalidad que ejerció la fuerza de su poder para legarnos su propia Historia, la que no tiene por qué ser asimilada como la nuestra, ya que "la historia no es todo el pasado" (Halbwachs, 1967: 209), sino que es solo una parte que interesa a quien la escribe.

En este entendido se nos presenta el problema teórico de nuestro trabajo, ya que debemos preguntarnos: dónde residen las diferentes formas de la Historia, cuáles son sus características y por qué la Nueva Crónica de Indias viene a ser una forma contrahistórica. Siguiendo a Ricouer podríamos indicar que un primer problema de la forma de la Historia radica en su representación, pues en su artículo Historia y memoria. La escritura de la historia y la representación del pasado (2000), indica que la problemática de la Historia está en la representación y sus re-construcciones, las que intentan cumplir con el llamado pacto de verdad entre autor y lector. Así, para el filósofo francés, el término representación designa "la relación de la memoria con el pasado bajo las especies de la imagen-recuerdo en un extremo de nuestro recorrido, y en el otro, hacia el cual nos dirigimos, la relación de la historia con el pasado, o sea, la intencionalidad misma del discurso histórico" (2000: 18). Es decir, ante nuestra pregunta acerca del lugar de residencia o mejor dicho dónde se origina el problema de las formas de la historia, viene a ser respondida primeramente por la representación, situando a su vez el origen de esta no en la Historia sino en la memoria (Ricoeur, 2000).

Ahora bien, si partimos tal como nos lo propone Ricoeur en la memoria, llegamos a un fértil terreno de origen de la contrahistoria porque es en la sobrevivencia de un recuerdo transmitido en el que se materializó una resistencia a los dominios impuestos desde Occidente, mediante la escritura y enseñanza de su discurso histórico, cuya finalidad terminó siendo política, ideológica y disciplinaria. De ahí 
entonces, tenemos que como expresión contradiscursiva una contrahistoria se abordaría desde fuera de los cauces oficiales de la Historia, en las emergencias marginales que harían cuestionamientos a su aparato institucional por otras vías de expresión, sean: testimonios, pinturas, cuentos, novelas, canciones, poemas u otros. Por tal motivo, una primera característica que obtenemos sobre las formas de la Historia es que como expresión de un momento histórico dado puede tener una manifestación indefinida materialmente, pero del mismo modo no posee una determinación temporal, pues las vicisitudes para la sobrevivencia de una expresión no permiten limitar esa misma expresión contrahistórica a un único momento para su emergencia, siendo esto último lo que nos permite justificar la mirada contemporánea sobre un hecho del pasado remoto, como es el tes-CUBRIMIENTO en las novelas El arpa y la sombra y Los perros del paraiso.

\section{LA NUEVA CRÓNICA DE INDIAS COMO EXPRESIÓN DE UNA CONTRAHISTORIA}

Un primer acercamiento al concepto de Nueva Crónica de Indias lo haremos desde el llamado de Carpentier a los novelistas latinoamericanos y observando la forma que revestía la Crónica de Indias. Nos parece interesante esta conceptualización del escritor cubano por su doble dimensión, pues por una parte propone un quehacer crítico en la misma historia emergida en las novelas, y por otra dar cuenta de la realidad contemporánea de América Latina, exigiendo a los autores un compromiso político con las causas justas, ya que para él hablar de "la neutralidad de la cultura es un absurdo" (1981: 29).

No obstante, el sentido que cobraba el término Nueva Crónica de Indias remonta inmediatamente al des-CUBRIMIENTO, en donde la crónica surge como una nueva forma de historiar llamada Crónicas Reales, "cuyo estilo epistolar, servía de informe a la corona y constituía una especie de bitácora de tierra a los conquistadores. Por sus propósitos, se centran en la descripción de los aspectos militares, en actos victoriosos y la descripción de la gente y el paisaje quedan subordinados al primero" (Brenes, 1994: 8). En este sentido, entonces, Carpentier señala que el novelista, dentro del contexto de los hombres pensantes, pertenece a una particular especie: "La especie de los cronistas, destinados a repertoriar los acontecimientos de su época que le sean perfectamente inteligibles"(1981:23).

Y continúa indicando:

Ante una tecnología invasora omnipresente, de una acceso cada vez más difícil, por no decir imposible, para el novelista latinoamericano, éste sólo podrá hallar su razón de ser en erigirse en una suerte de Cronista de Indias de su continente, trabajando 
en función de la historia moderna y pasada de ese continente, mostrando a la vez, sus relaciones con la historia del mundo todo, cuyas contingencias también le atañen, poco o mucho (Carpentier, 1981: 30).

Crónicas que inician las grandes novelas para nuestro autor, pero que además, para nosotros, producen un verdadero quiebre epistémico con la historia, pues si con Halbwachs veíamos que la Historia surgía luego de un distanciamiento de la tradición ${ }^{2}$ y, por tanto, de cualquier individualidad o particularidad subjetiva como un vestigio del positivismo, con Carpentier vemos que el punto hacia la historia emerge justamente desde la particularidad hacia el todo, es decir, desde la narración de la vida misma se debe retratar la Historia con el mismo espíritu de un cronista.

\section{EL ARPA Y LA SOMBRA}

Esta novela, escrita por Carpentier y publicada en 1979 viene a ser una obra en que se expresan los elementos que caracterizan al grupo de novelas que integran el corpus de la Nueva Crónica de Indias. La mirada crítica y liberadora que se produce en el texto marcan en la lectura del relato una intención de parte del autor, en sentido inverso al que declaraba Ricoeur con el pacto de verdad entre el autor y el lector de la historia, pues acá se intenta develar e incluso desacralizar a un personaje del cual poco o casi nada sabemos, salvo el título de descubridor, por lo que el pacto estaría entonces no en la verdad, sino un la posibilidad de que aquella no lo sea. En este sentido, la novela no busca ser historia, ni verdad, sino muy por el contrario, una contrahistoria.

...el descubrimiento del Nuevo Mundo por Cristóbal Colón era el máximo acontecimiento contemplado por el hombre desde que en el mundo se hubiese instaurado una fe cristiana y, gracias a la Proeza Impar, se habia doblado el espacio de las tierras y mares conocidos a donde llevar la palabra del Evangelio... Y, junto a la respetuosa solicitud, había, en foja separada, un breve mensaje dirigido a la Sacra Congragación de Ritos que, al recibir el aval de la firma pontifica, echaría a andar, de inmediato, el intrincado proceso de la beatificación del Gran Almirante de Fernando e Isabel. Su Santidad tomó la pluma, pero la mano empezó a sobrevolar la página, como dubitativa, desmenuzando una vez más las implicaciones de cada palabra. Siempre ocurría así cuando se sentía más resuelto a trazar la rúbrica decisiva al pie de aquel documento. Y era porque en un párrafo del texto aparecía una frase,

\footnotetext{
2 "La historia solo comienza en el punto en que acaba la tradición, momento en que se apaga o descompone la memoria social” (Halbwachs, 1967: 212).
} 
especialmente subrayada, que siempre detenía su gesto: «...pro introductione illius causae exceptionali ordine». Esto de introducir la postulación "por vía excepcional» hacía vacilar, una vez más, al Sumo Pontífice. Era evidente que la beatificación -camino previo para la canonización- del Descubridor de América constituiría un caso sin precedente en los anales del Vaticano porque su expediente carecía de ciertos respaldos biográficos que, según el canon, eran necesarios al otorgamiento de una aureola (Carpentier, 1998: 18-19).

Para esto, Carpentier hace un uso de gestos muy específicos pero cargados de significados dentro de la mirada globalizante que exige al lector y a sí mismo como autor, pues usa las fuentes primarias como parte de una ficción posible con epígrafes, notas al pie y datos históricos reales.

Visto así, entonces, en la novela emerge un discurso contrahistórico que se enfrenta a una hegemonía discursiva ${ }^{3}$, impuesta por la vía institucional, que habla de descubrimiento, y aunque esta noción ya venía siendo puesta en cuestión hacía un tiempo, el gesto de Carpentier está contenido en la propia narración sobre Colón, pues al develarlo embustero, ambicioso y mentiroso lo desacraliza y despoja de su único título, haciendo de esto el tema de su relato: la canonización de Cristóbal Colón, primero por el papa Pío IX y luego por León XIII.

Pero entre los muchos elementos con que arma o mejor dicho desarma Carpentier a Colón hay uno que se posa en todos los espacios posibles sin encontrar solución, la biografía del almirante, pues dice en una intervención del narrador:

Era evidente que la beatificación -camino previo para la canonización- del Descubridor de América constituiría un caso sin precedente en los anales del Vaticano porque su expediente carecía de ciertos respaldos biográficos que, según el canon, eran necesarios al otorgamiento de una aureola (Carpentier, 1998:18-19).

El tema, el hecho histórico y la forma de esta novela no solo nos hablan de una Nueva Crónica, sino de una búsqueda de liberación de personajes "heroicos" que significaron también dolor, muerte, esclavitud y la pérdida de identidad. En

\footnotetext{
3 "La escritura es justamente la memoria de la hegemonía, pero por ser la memoria de hegemonía es la explicitación de la estructura y, por ende, la condición de posibilidad de la hegemonía alternativa. Esto, desde un punto de vista gramsciano, es fundamental: es importante que la hegemonía en algún momento se revele, se manifiesta. Si la hegemonía no se manifiesta, reaparece el dualismo, la intencionalidad y otras prácticas, en última instancia, conservadoras. En cambio, la escritura es, desde una perspectiva gramsciana o bachtiniana, la explicitación de la hegemonía, un modo de decir que el mundo de las intenciones dualísticas es incontrastable.

"La escritura es una práctica, la explicitación de la hegemonía es una práctica. La escritura es, justamente, la memoria de la práctica y la conditio sine qua non de toda revolución"(Mancuso, 2005: 57). Cursivas del autor.
} 
un pasaje final del texto que describe la discusión dada sobre la beatificación de Colón se pone en evidencia el reclamo que señalamos:

Pero ahora, el discurso de Verne se hace seco y preciso como el de un profesor de matemáticas: "Por este viaje, el viejo mundo asumia la responsabilidad de la educación moral y politica del mundo nuevo. ¿Pero, acaso estaba a la altura de esa tarea, con tantas ideas estrechas como acarreaba, sus impulsos semi-bárbaros, sus odios religiosos...? Por lo pronto, empezó Colón por apresar a varios indios, con el propósito de venderlos en España» "iLlamo la atención del Tribunal, sobre el hecho de que Colón instituyó la esclavitud en el Nuevo Mundo!», clama, triunfante, el Abogado del Diablo. (El invisible ${ }^{4}$ sintió enfriarse su invisible cuerpo, como frío debía sentir el suyo, en toda la estación el Licenciado Vidriera.) «Se afirmó que esos indios eran caníbales. Pero ni en Baracoa ni en ninguna parte, encontró caníbales el navegante» (Carpentier, 1998: 166).

\section{LOS PERROS DEL PARAÍSO}

Esta novela que forma parte de la trilogía sobre el des-CUBRIMIENTO, del autor argentino Abel Posse, tiene una demandante exigencia de conocimientos sobre la historia cultural de Europa. Si en El arpa y la sombra era la desacralización de Colón en Los perros del paraíso es la desacralización de los "legados" culturales de Occidente. Posse ironiza cada uno de los símbolos históricos y culturales del viejo mundo: desde Colón y la reina hasta Nietzsche y las SS nazis, todo transfigurado con inteligencia para provocar en el lector una crítica a las significaciones y las herencias que ha traído la invasión europea.

La intertextualidad, los epígrafes, las cronologías y las constantes puestas en escena de pensamientos políticos fascistas de temporalidades superpuestas en el texto son una clara evidencia de una ironía radical contradiscursiva y contrahegemónica, por medio de la cual el autor pone bajo sospecha y somete a burla a la historia oficial.

Los nińos alcanzaron la sala de audiencias detrás de la mandona Isabel. Se cruzan con la pajamulta y las zalamecas de las prostitutillas de Corte que se alejan irreverentes. Piernas blanqueadas con polvo de yeso, según la moda. Caras en negro o violeta, párpados dorados. Grandes sombreros de espadachín flamenco con plumas amarillas, azules, verdes. Salen hacia el patio de mulas: les gusta galopar alocadamente por los sembrados espantando gallinas y labriegos pobres.

Penumbra. Un amanuense triste frente al libro de audiencias Aparentemente nadie. Pero en el rincón del eterno retorno de lo mismo, casi invisibles, el general

\footnotetext{
${ }^{4}$ Así llama el autor al espíritu de Colón.
} 
Queipo de Llano con altas botas muy lustradas y planchadísimos breeches preside la comitiva de académicos y magistrados (¿Díaz Plaja? ¿El doctor Derisi? ¿Battistesa? ¿D’Ors?). Le pedirán al Rey patrocinio y fondos para el Congreso de Cultura Hispánica de 1940 (Posse, 1994: 17).

La comprensión de este texto como expresión de una contrahistoria lo visualizamos en la ironía hacia lo positivo que pudo ser este "encuentro" de mundos (como lo llaman contemporáneamente), pero en el que Abel Posse ve solo un ridículo que presenta a lo largo de toda su novela. Es en este sentido, entonces, en el que leemos la descripción que hace de la idea sobre las nuevas tierras, nuestras tierras, en el pensamiento de Colón como un paraíso terrenal:

Conservaba ese lugar su esencia de no-muerte. Seguramente eran maravillosos jardines sin caída, sin manzanas arteras, sin serpientes parlantes, sin culpa. Habitados por otros adanes y con mujeres de deliciosos pelos largos, desnudas y gráciles como la difunta, protoancestro de Lady Godiva, que había aparecido en la playa de Galway (Posse, 1994: 131).

Un paraíso sin religión, que negaba todo lo que el catolicismo cuenta que se perdió, con las causas incluidas como una ironía que se imponía desde la institución católica. Pero además haciendo uso de la figura de Lady Godiva, protagonista de una leyenda anglosajona sobre la desnudez, de quien se indica que vivió en el siglo XI y que era famosa por su bondad y belleza. Intertextualidad recurrente que obliga al lector a una constante búsqueda de nombres y asociaciones de ideas para intentar dimensionar la profundidad de lo referido. Hacia el final de la novela nos dirá, criticando la forma absolutista y occidentalista que adquiere la mirada histórica, lo siguiente:

Eran esos centenares de perrillos del Paraíso (tal vez nostálgicos de Adán, como lo creían el Almirante y el lansquenete Swedenborg). Bestezuelas incapaces de ladrar que los primeros cronistas espańoles hasta llegaron a negarles naturaleza perruna, la "esencia de la perridad" como diría Heidegger. Algunos los describieron como "especie de roedores comestibles que no ladran pero emiten chillidos agudos si se los golpea”. Estos cronistas no sospechaban que sus almas, embebidas de las de sus amos muertos o desaparecidos, servían para guiarlos hacia el Todo, después del sobresalto de la vida (los toltecas los habían sacralizado e incluido en el Calendario. Todo perro podía ser nahual, continente de una desdichada alma humana) (Posse, 1994: 252). 


\section{LA CONTRAHISTORIA}

Comenzamos este texto haciendo referencia a las formas de la historia que han sido desarrolladas en nuestra América desde la invasión hispano-lusitana como formas hegemónicas de referir el pasado. Las exigencias metodológicas y de narración de la historia han sido cuestionadas por diferentes enfoques y teorías.

La historia tiene una serie de condicionantes metodológicas que no le permiten producir rupturas contrahistóricas con los discursos oficiales sobre el pasado. El apego metodológico que se le exige al historiador revela un carácter de sumisión epistémica en la actividad de revelar el pasado, siendo éste el principal fundamento de aceptación o rechazo, según sea el caso y la posición que se adopte, de su práctica entendida como disciplinar. En esto podemos hacer notar la dificultad epistemológica que se presenta al abordar el pasado, ya que tal como lo señala Boaventura de Souza Santos: "Las condiciones epistémicas de nuestras preguntas están inscritas en el reverso de los conceptos que utilizamos para darles respuesta" (2012: 20). Mientras que en el plano metodológico aparecen dos condiciones relevantes: la primera indicada por Paul Ricoeur en Historia y memoria (2000), donde postula la problemática exigencia que implica el pacto de verdad entre el autor y el lector: y la segunda, aportada por Luis Vitale, quien en su texto Sociología de la novela (2001) señala que "la historiografía tradicional contemporánea, heredera de la heurística decimonónica, sigue considerando sólo como fuente, llamada primaria, a los documentos, especialmente de carácter institucional" (Vitale, 2001: 9).

Con ambas posiciones vemos las dos caras de una misma moneda, pues por una parte están los fines asociados a la historia y por la otra las limitantes fuentes de las cuales se nutre la historiografía. Si bien, Foucault (2011) señala que una de las problemáticas de la historia consiste en "la revisión del valor del documento" (2011:15), documento que, como veíamos en Vitale, ejerce una limitante para el conocimiento histórico. El enfrentamiento de ese mismo documento con posiciones distintas de las oficiales lo lleva a ser interpretado de otras formas, arrojando resultados disímiles.

Hasta ahí este tramo aparece como algo complejo y por cierto que lo es. El punto está en cifrar el lugar de la novela, entendida como Nueva Crónica de Indias y por tanto un documento, no de verdad, pero sí de crítica a dicha verdad. No opone una "otra" verdad sino que emerge como un contradiscurso.

De este modo estas novelas dan cuenta de otra forma de abordar la realidad, expresando un compromiso con el que se intenta hacer frente a la Historia, es decir, adquiere un sentido contrahegemónico. Pero además, al nutrirse de documentos oficiales y datos históricos que reinterpreta a la luz de memorias que han sobrevivido y que permiten reinterpretar, poniendo bajo sospecha y en crisis a todo el discurso histórico, se nos presenta el sentido de estos discursos como expresión de una contrahistoria. 
Así, siguiendo al filósofo francés "El documento no es el instrumento afortunado de una historia que fuese en sí misma y con pleno derecho memoria; la historia es cierta manera, para una sociedad, de dar estatuto y elaboración a una masa de documentos de la que no se separa" (Foucault, 2011: 16), donde no sería por medio de una visión institucional, sino particular, de una expresión sobreviviente por la que emerge el documento en la novela.

\section{EL des-CUBRIMIENTO DE AMÉRICA O A MODO DE CIERRE}

La palabra descubrimiento, en el diccionario de la Real Academia Espańola de la Lengua, señala que proviene del verbo descubrir y este a su vez del latín discooperire. En todos sus casos de la primera acepción indica hallazgo, encuentro, manifestación de algo que estaba oculto o secreto o era desconocido. Mientras que en la segunda seńala: "Encuentro, invención o hallazgo de una tierra o un mar no descubierto o ignorado" (2006: 775). Y en su última indicación dice: "Territorio, provincia o cosa que se ha reconocido o descubierto". Pero en todas las formas adaptadas, inclusive a posterior del hecho histórico, vemos que no involucra "conquista", "apropiación", "dominio", ni "invasión". Junto a esto, debemos indicar que tampoco se señala que des-cubrimiento o des-cubrir es una palabra compuesta en su origen latino. Pues el verbo dis-cooperire posee la preposición $D I S$ y el verbo COOPERIO.

Dis - Di (Des): "son dos preposiciones latinas inseparables que por lo general denotan separación, tal como sucede en dis-traer. [...] La idea de separación y de división fácilmente tiene afinidad con la de negación y así es cómo dis y di suelen connotar este sentido" (Vilches, 1940: 98). Mientras que el verbo Cooperio -rui -rtum "tr. Cubrir enteramente" (Vox, 2003: 113). Siguiendo esto, deberíamos decir entonces que descubrimiento es reconocimiento, sin embargo, el sentido histórico que tuvo este hecho denominado así, no fue más que el CUBRIMIENTO de culturas que habitaban este continente. De ahí entonces que, siguiendo a O'Gorman veamos en el hecho referido por ambas novelas, El arpa y la sombra y Los perros del paraíso, como una negación e invasión de una cultura más avanzada militarmente. No obstante, el hecho no se detiene ahí, pues el llamado descubrimiento no pasaría de ser una interpretación sobre un hecho.

La tesis es esta: que a llegar Colón el 12 de octubre de 1492 a una pequeña isla que él creyó pertenecía a un archipiélago adyacente a Japón fue como descubrió América. Bien, pero preguntemos si eso fue en verdad lo que él, Colón, hizo o si es lo que ahora se dice que hizo. Es obvio que se trata de lo segundo y no de lo primero. Este planteamiento es decisivo, porque revela de inmediato que cuando 
los historiadores afirman que América fue descubierta por Colón no describen un hecho de suyo evidente, sino que nos ofrecen la manera en que, según ellos, debe entenderse un hecho evidentemente muy distinto: es claro, en efecto, que no es lo mismo llegar a una isla que se cree cercana a Japón que revelar la existencia de un continente de la cual, por otra parte, nadie podía tener entonces ni la menor sospecha. En suma, se ve que no se trata de lo que se sabe documentalmente que aconteció, sino de una idea acerca de que se sabe que aconteció ( $\mathrm{O}^{\prime}$ Gorman, 2006: 22).

Visto así el suceso histórico, con distintos matices y problematizaciones, tenemos que la Nueva Crónica de Indias, como denominó Alejo Carpentier a las narrativas de América Latina, son una expresión que se rebela contra un discurso, contra una dominación, contra lo dicho por esa supuesta verdad guardada en la Historia. El descubrimiento, entonces, a partir de lo narrado por Carpentier y Posse es un tes-CUBRIMIENTO, lleno de elementos ajenos a los hechos y a nuestro propio sentir acerca del pasado. La novela se vuelve así una expresión de contrahistoria.

\section{REFERENCIAS}

Bouzas, Patricia. El constructivismo de Vigotsky. Pedagogía y aprendizaje como fenómeno social. Buenos Aires: Longseller, 2004.

Brenes, Raymundo. "Interpretaciones históricas en torno al descubrimiento de América”, Revista de Historia de América 117 (1994): 7-22.

Carpentier, Alejo. La novela latinoamericana en vísperas de un nuevo siglo y otros ensayos. Madrid: Siglo XXI, 1981.

Carpentier, Alejo. El arpa y la sombra. Madrid: Alianza, 1998.

Donoso, José. Historia personal del "Boom”. Santiago de Chile: Andrés Bello, 1987.

Foucault, Michel. La arqueología del saber. Buenos Aires: Siglo XXI, 2011.

Guerra, Sergio. Cinco siglos de historiografia latinoamericana. La Habana: Editorial de Ciencias Sociales, 2009. 
Halbwalchs, Maurice. "Memoria histórica y memoria colectiva", Revista española de investigaciones sociológicas, (1967): 209-219. Disponible en: http://www. reis.cis.es/REIS/jsp/REIS.jsp?opcion=articulo\&ktitulo=1036\&autor $=M A$ URICE+HALBWACHS [Consultado el: 4 de junio de 2013].

Mancuso, Hugo. La palabra viva. Teoría verbal y discursiva de Michail Bachtín. Buenos Aires: Paidós, 2005.

O'Gorman, Edmund. La invención de América. México: Fondo de Cultura Económica, 2006.

Pizarro, Ana. De ostras y caníbales. Ensayos sobre la cultura latinoamericana. Santiago de Chile: Editorial Universidad de Santiago, 1994.

Pizarro, Carolina. “¿Debería aceptar yo sin más, las paparruchas y embustes de vuestros cronistas?”, Revista Alpha 31 (2010): 215-230.

Ricoeur, Paul. "Historia y memoria. La escritura de la historia y la representación del pasado". Historizar el pasado vivo en América Latina. Pérotin-Dumon. Disponible en: http://etica.uahurtado.cl/historizarelpasadovivo/es_contenido. php [Consultado el: 4 de junio de 2013].

Tozzi, Verónica. La historia según la nueva filosofía de la historia. Buenos Aires: Prometeo, 2009.

Vilches, Roberto. Raices griegas y latinas. Prefijos y sufijos. Santiago de Chile: Nascimento, 1940.

Vitale, Luis. Sociología de la novela y vida cotidiana en el Chile de 1900 a 1950. Santiago de Chile: Puerto de Palabras, 2001.

Viu, Antonia. "Una poética para el encuentro entre historia y ficción”, Revista chilena de literatura 70 (2007): 167-178.

VV.AA. Diccionario ilustrado Latín. Barcelona: Vox, 2003. 